\title{
STUDY ON MEASUREMENT METHOD OF FLOW-RATE CHARACTERISTICS OF PNEUMATIC SOLENOID VALVE
}

\author{
Kiyoshi KUROSHITA \\ Department of Mechanical Engineering \\ Numazu College of Technology \\ 3600 Ooka, Numazu, Shizuoka, 410-8501 Japan \\ (E-mail: kuro@mech.numazu-ct.ac.jp)
}

\begin{abstract}
The test method for the flow characteristics of a pneumatic solenoid valve is specified in ISO 6358 . In this standard, the flow characteristics are shown by the sonic conductance and the critical pressure ratio, and these are calculated from the flow rate, the pressure and the temperature of the air that passes the solenoid valve. When the flow characteristics of a large solenoid valve are measured by this method, a large compressor and a large flow meter are required. Therefore the power consumption and the generating noise become very large. In this study, a test method using the small and low noise test equipment is developed. In this method, at first the tank connecting to the solenoid valve is evacuated, and then the air is charged in the tank through the solenoid valve from the atmosphere. By using the pressure and temperature in this tank, the sonic conductance and the critical pressure ratio are evaluated.
\end{abstract}

\section{KEY WORDS}

Pneumatic solenoid valve, Charge method, Polytropic change, Sonic conductance, Critical pressure ratio

\section{NOMENCLATURE}

$b \quad$ : Critical pressure ratio [pure number]

$C$ : Sonic conductance $\left[\mathrm{m}^{4} \cdot \mathrm{s} / \mathrm{kg}\right]$

$M$ : Mass of air $[\mathrm{kg}]$

$n$ : Polytropic index [pure number]

$P$ : Absolute pressure [Pa]

$q_{v}:$ Volume flow rate at standard reference conditions(ANR) $\left[\mathrm{m}^{3} / \mathrm{s}\right]$

$R \quad:$ Gas constant $[\mathrm{J} /(\mathrm{kg} \cdot \mathrm{K})]$

$t \quad:$ Time [s]

$T$ : Absolute temperature $[\mathrm{K}]$

$V \quad:$ Volume $\left[\mathrm{m}^{3}\right]$

$\rho:$ Mass density $\left[\mathrm{kg} / \mathrm{m}^{3}\right]$

\section{INTRODUCTION}

The test method for the flow characteristics of a pneumatic solenoid valve is specified in ISO 6358 [1]. In this standard, the flow characteristics of a solenoid valve are shown by the sonic conductance and the critical pressure ratio, and these are calculated from the flow rate, the pressure and the temperature of the air that flows through the solenoid valve. This test method is normally called the flow method. When the flow characteristics of a large solenoid valve are measured by this method, a large compressor and a large flow meter are required. Therefore the power consumption and the generating 
noise that arises during the test become very large. A test method that can obtain the critical pressure ratio and the sonic conductance by using the small and low noise test equipment is developed [2]. In this test method, at first the tank connecting to the solenoid valve that is to be measure for the flow characteristics is evacuated, and then the air is charged in the tank through the solenoid valve from the atmosphere. By using the pressure and the temperature in this tank, the sonic conductance and the critical pressure ratio of the solenoid valve are evaluated. In this report, this test method is named the charge method.

\section{FUNDAMENTAL EQUATIONS}

Figure 1 shows the schematic diagram of the charge method. The change of state of the air in the tank is considered when the air is charged to the tank in vacuum state through the tested solenoid valve from the atmosphere. In this figure, $P$ is the absolute pressure of the air in the tank $[\mathrm{Pa}], V$ is the volume of the air $\left[\mathrm{m}^{3}\right], T$ is the absolute temperature of the air $[\mathrm{K}], M$ is the mass of the air $[\mathrm{kg}], q_{v}$ is the volume flow rate at standard conditions $\left[\mathrm{m}^{3} / \mathrm{s}\right], C$ is the sonic conductance $\left[\mathrm{m}^{4} \cdot \mathrm{s} / \mathrm{kg}\right], b$ is the critical pressure ratio [pure number].

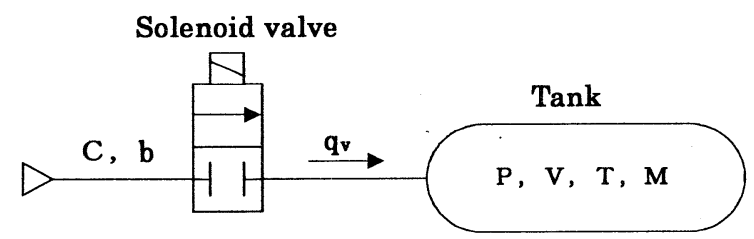

Figure 1 Schematic diagram of charge method

Under charging, the air with the mass $M$ in the tank is compressed by the air of mass $d M$ that flows in the tank during the time $d t$, and the pressure $P$ increases by $d P$, and the volume $V$ decreases by $d V$. If the change of state of the air in the tank is assumed polytropic change, the next relational expression can be established between the pressure $d P$ and the volume $d V$.

$$
V d P=n P d V
$$

Where, $n$ is the polytropic index. Since the volume of the air in the tank $V$ is equal to the internal volume of the tank $V_{0}$, the following equation can be obtained.

$$
d V=\frac{V_{0}}{n P} d P
$$

Now, it is assumed that the air is the ideal gas, and that the air flows through the solenoid valve from the atmosphere in the space volume $d V$ generated by compressing the air in the tank and rests. In such occasions, the temperature of the air that is filled in the space volume $d V$ equals the room temperature [4]. When the minute term of high order is neglected, the state equation of the air that is filled in the space volume $d V$ can be expressed as

$$
P d V=R T_{1} d M
$$

Where, $T_{1}$ is the room temperature, and $R$ is the gas constant of air. From the continuity equation, the following equation can be obtained.

$$
q_{v}=\frac{1}{\rho_{0}} \frac{d M}{d t}=\frac{R T_{0}}{P_{0}} \frac{d M}{d t}
$$

Where, $\rho_{0}$ is the mass density of air at the standard reference conditions (ANR), i.e. the absolute temperature $T_{0}=293.15 \mathrm{~K}$, the absolute pressure $P_{0}=100 \mathrm{kPa}$, the relative humidity $65 \%$.

From Eq.(2), Eq.(3) and Eq.(4), the following equation is given,

$$
q_{v}=\frac{V_{0}}{n P_{0}} \frac{T_{0}}{T_{1}} \frac{d P}{d t}
$$

For choked flow, i.e. when $P / P_{1} \leq b$

For this case, the volume flow rate $q_{v}$ that flows through the solenoid valve is shown by the following equation according to ISO 6358 .

$$
q_{v}=C P_{1} \sqrt{\frac{T_{0}}{T_{1}}}
$$

Where, $P_{1}$ is the upstream absolute pressure of the solenoid valve, $T_{1}$ is the upstream absolute temperature. From Eq.(5) and Eq.(6), the following equation is given,

$$
\frac{d P}{d t}=\frac{n C P_{0} P_{1}}{V_{0}} \sqrt{\frac{T_{1}}{T_{0}}}
$$

When Eq.(7) is integrated from the start time of charge $(t=0)$ to the any time $(t=t)$, the following equation can be obtained.

$$
P=\frac{n C P_{0} P_{1}}{V_{0}} \sqrt{\frac{T_{1}}{T_{0}}} t+P_{i}
$$

Where, $P_{i}$ is the initial pressure in the tank and $P$ is the pressure at the time $t$. Eq.(8) shows that the time variation of pressure $P$ is the straight line for the choked flow. And, the sonic conductance $C$ is shown by the following equation, when Eq.(7) is rearranged. 
$C=\frac{V_{0}}{n P_{0} P_{1}} \sqrt{\frac{T_{0}}{T_{1}}} \frac{d P}{d t}$

Then, the sonic conductance $C$ can be calculated using the value of gradient $d P / d t$ in the straight section for the choked flow of the measured pressure change.

\section{For subsonic flow, i.e. when $\boldsymbol{P} / \boldsymbol{P}_{\mathbf{1}}>\boldsymbol{b}$}

For this case, the volume flow rate $q_{v}$ that flows through the solenoid valve is shown by the following equation according to ISO 6358 .

$q_{v}=C P_{1} \sqrt{\frac{T_{0}}{T_{1}}} \sqrt{1-\left(\frac{\frac{P}{P_{1}}-b}{1-b}\right)^{2}}$

Where, $P$ is the downstream absolute pressure of the solenoid valve, $b$ is the critical pressure ratio. From Eq.(5) and Eq.(10), the following equation is given,

$\frac{d P}{d t}=\frac{n C P_{0} P_{1}}{V_{0}} \sqrt{\frac{T_{1}}{T_{0}}} \sqrt{1-\left(\frac{\frac{P}{P_{1}}-b}{1-b}\right)^{2}}$

When Eq.(11) is integrated from the time $\left(t=t_{c}\right)$ to the any time $(t=t)$ and the relation of $P_{c} / P_{1}=b$ is substituted, the following equation can be obtained.

$$
P=(1-b) P_{1} \sin \left\{\frac{n C P_{0}}{V_{0}(1-b)} \sqrt{\frac{T_{1}}{T_{0}}}\left(t-t_{c}\right)\right\}+b P_{1}
$$

Where, $t_{c}$ is the time when the pressure in the tank reached the critical pressure $P_{c}$. Then the time variation of pressure $P$ is the sine curve for the subsonic flow.

When the values $\left(t_{n}, P_{n}\right)$ and $\left(t_{n+1}, P_{n+1}\right)$ are substituted in Eq.(12) and $t_{c}$ is eliminated, the following equation can be obtained.

$(1-b)\left\{\sin ^{-1}\left(\frac{\frac{P_{n+1}}{P_{1}}-b}{1-b}\right)-\sin ^{-1}\left(\frac{\frac{P_{n}}{P_{1}}-b}{1-b}\right)\right\}=\frac{n C P_{0}}{V_{0}} \sqrt{\frac{T_{1}}{T_{0}}}\left(t_{n+1}-t_{n}\right)$

Substituting the values $\left(t_{n}, P_{n}\right)$ and $\left(t_{n+1}, P_{n+1}\right)$ of two points of the measured pressure in Eq.(13) and solving this equation, the critical pressure ratio $b$ can be obtained. Although it is difficult to obtain the analytic solution of Eq.(13), the critical pressure ratio can be easily obtained by the numerical analysis by using the off-the-shelf software. The method for obtaining polytropic index $n$ under charging is shown as follows. The absolute temperature at the end of charge $T_{f}$ is given by the following equation [4].

$$
T_{f}=\frac{n}{1+\frac{P_{i}}{P_{f}}(n-1)} T_{i}
$$

Where, $T_{i}$ and $P_{i}$ are the temperature and the pressure at the start of charge respectively, and $P_{f}$ is the pressure at the end of charge. Since the value of $P_{i} / P_{f}$ is about 0.02 for the charge method, the next approximate expression has the sufficient accuracy.

$n=\frac{T_{f}}{T_{i}}$

\section{EXPERIMENTAL APPARATUS}

Figure 2 shows the schematic diagrams of the experimental apparatus and Figure 3 is a photograph of the tested valve $(50 \mathrm{~mm}$ nominal bore) and the tank $\left(V_{0}=2209 \mathrm{dm}^{3}\right)$. By connecting the tubes specified in JIS B 8390 to the inlet and outlet ports of the tested valve, the consistency with the flow method in ISO 6358 was attempted.

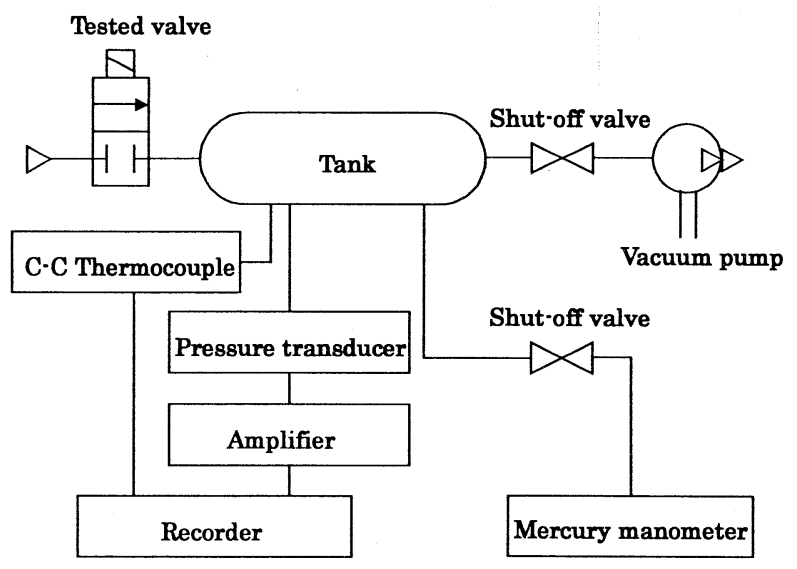

Figure 2 Experimental apparatus

The experimental method is shown as follows. By the vacuum pump, the gauge pressure in the tank is reduced to about $-98 \mathrm{kPa}$. Then, the shut-off valve connected to the vacuum pump is closed, and it is left until the pressure and the temperature in the tank become a steady state. Next, by opening the tested valve, the atmospheric air is charged in the tank, and the pressure under charging is detected by the pressure transducer and the temperature is detected by the copper-constantan thermocouple of the $0.2 \mathrm{~mm}$ diameter. They are recorded 
in the digital recorder. The mercury manometer was used for the calibration of the pressure transducer, and the atmospheric pressure was measured by the aneroid barometer.

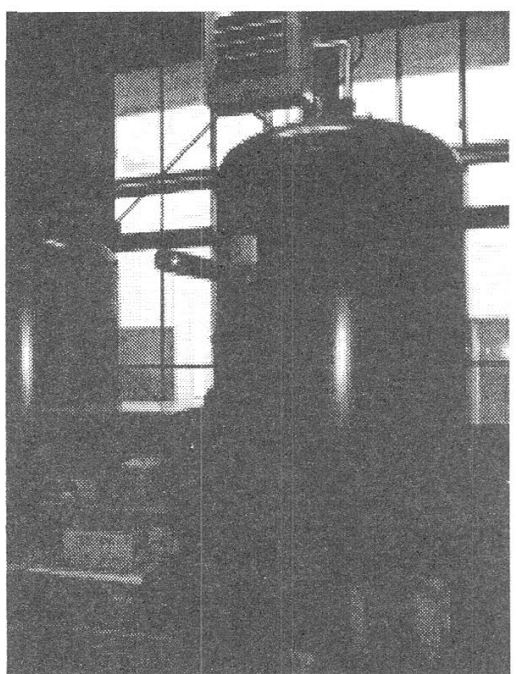

Figure 3 Tested valve (50 $\mathrm{mm}$ Nominal bore) and tank $\left(V_{0}=2209 \mathrm{dm}^{3}\right)$

\section{EXPERIMENTAL RESULTS}

First, the flow characteristic of the restriction (the cylindrical restriction of $D=5.18 \mathrm{~mm}$ diameter and $L=5.0 \mathrm{~mm}$ length) measured by the charge method is shown. The restriction does not have the control function of the flow. Then, the flow of the restriction was controlled by the tested valve $\mathrm{H}$ in Table 3 that has about 5 times of the sonic conductance of the restriction.

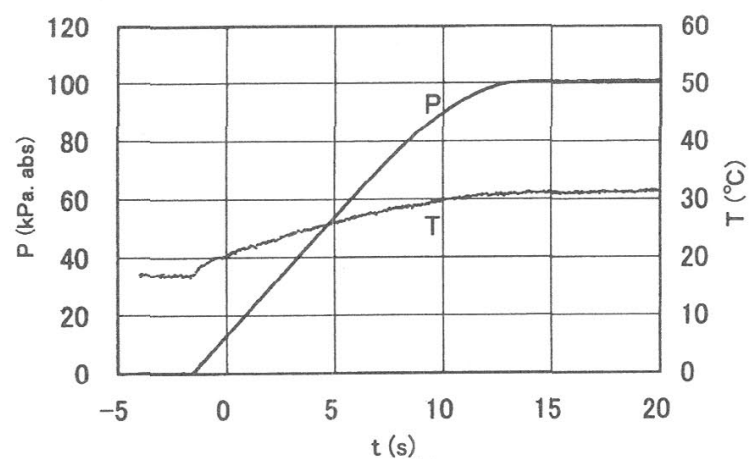

Figure 4 Pressure and temperature change in tank Diameter of restrictor $D=5.18 \mathrm{~mm}$ $C=3.71 \mathrm{dm}^{3} /(\mathrm{s} \cdot \mathrm{bar}), b=0.514$

$P_{1}=101.0 \mathrm{kPa}(\mathrm{abs}), T_{1}=292.15 \mathrm{~K}, V_{0}=47.78 \mathrm{dm}^{3}$

Figure 4 shows the pressure and the temperature in the tank. Just after the start of charge, the pressure change is the straight line, and then the flow in the restriction is the choked flow. On the way, the pressure change becomes the sine curve, and the flow in the restriction becomes the subsonic flow.

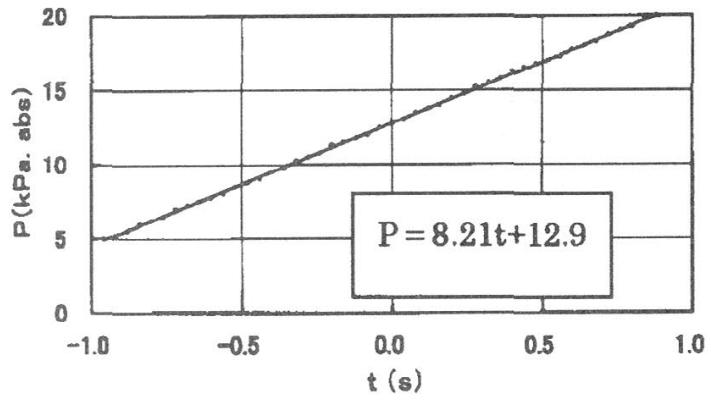

Figure 5 Straight section of pressure change

The straight section of pressure change under charging was extracted in Figure 5. From the regression formula of this straight line, the time derivative of the pressure $d P / d t$ was obtained, and its value was $8.21 \mathrm{kPa} / \mathrm{s}$. Furthermore, the polytropic index $n$ was obtained by Eq (15) using the temperature at the start of charge $\left(17.0^{\circ} \mathrm{C}\right)$ and the temperature at the end of charge $\left(31.2^{\circ} \mathrm{C}\right)$ of the temperature change in Figure 4 , and then $n=1.048$. Substituting these values in Eq.(9), the sonic conductance $C$ was obtained, and consequently $C=3.71 \mathrm{dm}^{3} /(\mathrm{s} \cdot \mathrm{bar})$. Here, the unit of sonic conductance $C$ is the practical unit allowed in ISO 6358. Moreover, the combination error of sonic conductance was determined by the root mean square method [1] using the actual systematic errors of the pressure, the temperature, the time, etc. and its value was $0.97 \%$. The temperature change was measured at the position of $75 \mathrm{~mm}$ distance from the inside wall of the tank.

Table 1 Critical pressure ratio

\begin{tabular}{|c|c|c|c|c|}
\hline $\begin{array}{c}P \sim P_{T} \\
{[\%]}\end{array}$ & $\begin{array}{c}t \\
{[s]}\end{array}$ & $\begin{array}{c}P \\
{[\text { bar(abs.) }}\end{array}$ & $\begin{array}{c}\text { Range } \\
{[\%]}\end{array}$ & $\begin{array}{c}b \\
{[-]}\end{array}$ \\
\hline 90 & 10.24 & 0.9100 & $80 \sim 90$ & 0.536 \\
\hline 80 & 8.52 & 0.8075 & $70 \sim 80$ & 0.513 \\
\hline 70 & 7.12 & 0.7075 & $60 \sim 70$ & 0.556 \\
\hline 60 & 5.84 & 0.6050 & $50 \sim 60$ & 0.450 \\
\hline 50 & 4.60 & 0.5050 & \multicolumn{2}{|c|}{ Mean value $b=0.514$} \\
\hline
\end{tabular}

From the pressure change in Figure 4, the times and the pressures at the point of $50 \%$ and $60 \%, 60 \%$ and $70 \%$, $70 \%$ and $80 \%, 80 \%$ and $90 \%$ of the pressure at the end of charge (the atmospheric pressure $\mathrm{P}_{1}$ ) were obtained as shown in Table 1. The critical pressure ratio $b$ was calculated by substituting these values in Eq.(13), and then the mean value of these critical pressure ratios was 0.514 . 


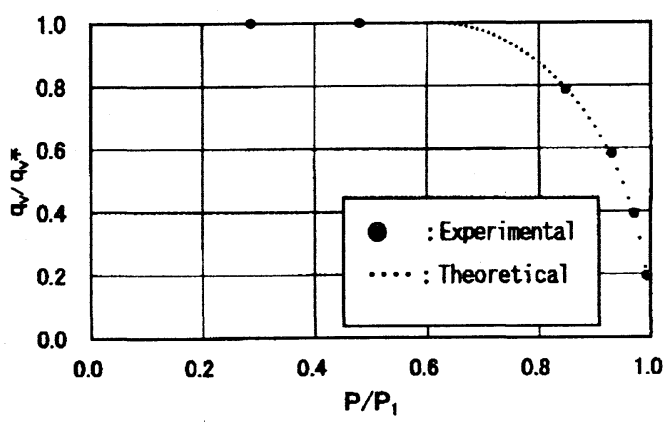

Figure 6 Pressure - flow characteristics by flow method Diameter of restrictor $D=5.18 \mathrm{~mm}$ $C=3.70 \mathrm{dm}^{3} /(\mathrm{s} \cdot \mathrm{bar}), b=0.610$

$P_{1}=500 \mathrm{kPa}(\mathrm{abs}), T_{1}=292.25 \mathrm{~K}, q_{v}{ }^{*}=18.41 \mathrm{dm}^{3} / \mathrm{s}(\mathrm{ANR})$

Figure 6 shows the pressure-flow characteristic of the restriction measured by the flow method specified in ISO 6358. Substituting the flow rate, the pressure and the temperature of the choked flow for the equation regulated in ISO 6358 , the sonic conductance $C$ was calculated, and then $C=3.70 \mathrm{dm}^{3} /(\mathrm{s} \cdot \mathrm{bar})$. Moreover, substituting the flow rate and the pressure of the subsonic flow for the equation regulated in ISO 6358, the critical pressure ratio $b$ was calculated, and then $b=0.610$. The symbol $(\bullet)$ in the figure shows the experimental values, and the broken line shows the calculated value of flow rate that was obtained by substituting the measured values of $C$ and $b$ for the equation regulated in ISO 6358 . The symbol $q_{v}{ }^{*}$ is the volume flow rate of the choked flow. Supposing that the coefficient of viscosity of air is
$18.21 \times 10^{-6} \mathrm{~Pa} \cdot \mathrm{s}$ and calculating the Reynolds number $R e$ in the restriction, $R e=5.94 \times 10^{4}$ in the charge method and $R e=2.97 \times 10^{5}$ in the flow method. When the discharge coefficient $C_{d}$ is calculated in regarding the restriction as a critical nozzle [5], $C_{d}=0.984$ in the charge method and $C_{d}=0.992$ in the flow method. Since the sonic conductance is dependent only on the discharge coefficient, the sonic conductance given by the charge method is about $0.8 \%$ smaller than that by the flow method. Next, assuming a $50 \mathrm{~mm}$ nominal bore solenoid valve as a critical nozzle of the $33 \mathrm{~mm}$ diameter and calculating the Reynolds number under the same condition, $R e=3.82 \times 10^{5}$ in the charge method and $R e=1.91 \times 10^{6}$ in the flow method. When the discharge coefficient $C_{d}$ is calculated, $C_{d}=0.993$ in the charge method and $C_{d}=0.996$ in the flow and so the sonic conductance given by the charge method is about $0.3 \%$ smaller than the value by the flow method. Therefore, the value of the sonic conductance measured by the charge method agrees well with that by the flow method for the large solenoid valve.

Next, the flow characteristic of the solenoid valve and the restriction obtained by the charge method, the flow method and the discharge method specified in Annex E of JIS B 8390 [3] are shown in Table 2. In the case of the small solenoid valve, the values of sonic conductance $C$ measured by the charge method agree well with the values obtained by the flow method and the discharge method.

Table 2 Experimental results

\begin{tabular}{|c|c|c|c|c|c|c|c|c|c|}
\hline \multirow{2}{*}{$\begin{array}{c}\text { Tested } \\
\text { Valve } \\
\text { and } \\
\text { Restrictor }\end{array}$} & \multicolumn{3}{|c|}{$\begin{array}{c}\text { Sonic conductance } C \\
{\left[\mathrm{dm}^{3} /(\mathrm{s} \cdot \text { bar })\right]}\end{array}$} & \multicolumn{3}{|c|}{$\begin{array}{c}\text { Critical Pressure Ratio } b \\
{[-]}\end{array}$} & \multirow{2}{*}{$\begin{array}{c}\text { Diameter of } \\
\text { Connecting } \\
\text { Tube } \\
{[\mathrm{mm}]}\end{array}$} & \multirow{2}{*}{\begin{tabular}{|c|} 
Nominal \\
Bore \\
{$[\mathrm{mm}]$} \\
\end{tabular}} & \multirow{2}{*}{ Note } \\
\hline & \begin{tabular}{c|} 
Flow \\
Method
\end{tabular} & \begin{tabular}{|l|} 
Charge \\
Method
\end{tabular} & \begin{tabular}{|c|} 
Discharge \\
Method
\end{tabular} & \begin{tabular}{|c|} 
Flow \\
Method
\end{tabular} & \begin{tabular}{l|} 
Charge \\
Method
\end{tabular} & $\begin{array}{c}\text { Discharge } \\
\text { Method }\end{array}$ & & & \\
\hline Valve $\mathrm{A}$ & 0.630 & \begin{tabular}{|l|}
0.618 \\
\end{tabular} & 0.612 & \begin{tabular}{|l|}
0.519 \\
\end{tabular} & 0.503 & *** & 6 & 6 & 2 Port Valve \\
\hline Valve $B$ & 1.26 & 1.30 & 1.27 & 0.517 & 0.542 & $* * *$ & 9 & 8 & 2 Port Valve \\
\hline Valve C & 2.33 & 2.39 & 2.33 & 0.233 & 0.252 & $* * *$ & 9 & 8 & 3 Port Valve \\
\hline Valve $D$ & 3.59 & 3.60 & 3.67 & 0.308 & 0.239 & $* * *$ & 9 & 8 & 3 Port Valve \\
\hline Valve $\mathrm{E}$ & $* * *$ & 9.23 & 9.32 & $* * *$ & 0.250 & $* * *$ & 13 & 10 & 3 Port Valve \\
\hline Valve $F$ & $* * *$ & 7.20 & 7.21 & $* * *$ & 0.211 & $* * *$ & 13 & 10 & 5 Port Valve \\
\hline Valve $\mathrm{G}$ & $* * *$ & 7.75 & 7.66 & $* * *$ & 0.176 & $* * *$ & 13 & 10 & 2 Port Valve \\
\hline Valve $H$ & $* * *$ & 17.7 & 17.6 & $* * *$ & 0.187 & $* * *$ & 16 & 15 & 2 Port Valve \\
\hline Valve I & $* * *$ & 25.3 & 25.0 & $* * *$ & 0.221 & $* * *$ & 22 & 20 & 3 Port Valve \\
\hline Valve $\mathrm{J}$ & $* * *$ & 50.6 & 51.1 & $* * *$ & 0.184 & $* * *$ & 28 & 25 & 2 Port Valve \\
\hline Valve $\mathrm{K}$ & $* * *$ & 54.8 & 55.3 & $* * *$ & 0.151 & $* * *$ & 36 & 32 & 2 Port Valve \\
\hline Valve L & $* * *$ & 123.5 & $* * *$ & $* * *$ & 0.216 & $* * *$ & 43 & 40 & 2 Port Valve \\
\hline Valve $M$ & $* * *$ & 132.5 & $* * *$ & $* * *$ & 0.228 & $* * *$ & 53 & 50 & 3 Port Valve \\
\hline Valve $\mathrm{N}$ & $* * *$ & 185.9 & $* * *$ & $* * *$ & 0.186 & $* * *$ & 53 & 50 & 2 Port Valve \\
\hline $\begin{array}{l}\text { Restrictor } \\
D=3.96 \mathrm{~mm}\end{array}$ & 2.10 & 2.12 & 2.12 & 0.585 & 0.564 & $* * *$ & 9 & - & $\begin{array}{l}\text { Controlled } \\
\text { by Valve } H\end{array}$ \\
\hline $\begin{array}{l}\text { Restrictor } \\
D=5.18 \mathrm{~mm}\end{array}$ & 3.70 & 3.71 & 3.75 & 0.610 & 0.514 & $* * *$ & 9 & - & $\begin{array}{l}\text { Controlled } \\
\text { by Valve } \mathrm{H}\end{array}$ \\
\hline
\end{tabular}


For the capacity shortage of the compressor, the test by the flow method was not possible on the medium and the large solenoid valves, and the critical pressure ratio cannot be obtained by the discharge method in principle. Therefore, it is difficult to evaluate the measurement accuracy of the critical pressure ratio obtained by the charge method for the large solenoid valve. However, by estimating from the measurement results of the small solenoid valve, it is guessed that the measurement accuracy of the critical pressure ratio obtained by the flow method is at the same level as that obtained by the charge method. Also in the case of the medium solenoid valve, the values of sonic conductance $C$ measured by the charge method agree well with the values obtained by the discharge method. On the large solenoid valve, the test by the discharge method was not carried out, because it was dangerous for the human body. In addition, the symbol (***) shows the item that could not be measured. The charge method is the only method for measuring the critical pressure ratio and the sonic conductance of the large solenoid valve at this time.

In the test of the valve $\mathrm{C}$ by the charge method, the equivalent sound level measured at the position of $1 \mathrm{~m}$ from the tested valve was $74.0 \mathrm{~dB}(\mathrm{~A})$, and the equivalent sound level under the test of the same valve by the flow method was $92.0 \mathrm{~dB}(\mathrm{~A})$. Moreover, the equivalent sound level at the test of the characteristic of the solenoid valve $\mathrm{N}$ (50mm nominal bore) by the charge method was about $100 \mathrm{~dB}(\mathrm{~A})$. Then, the charge method is extremely low noise in comparison with the conventional test method.

Table 3 Polytropic index

\begin{tabular}{|c|c|c|c|}
\hline $\begin{array}{c}\text { Distance from } \\
\text { wall surface } \\
{[\mathrm{mm}]}\end{array}$ & $\begin{array}{c}\text { Temperature } \\
\text { at start } \\
{\left[{ }^{\circ} \mathrm{C}\right]}\end{array}$ & $\begin{array}{c}\text { Temperature } \\
\text { at end } \\
{\left[{ }^{\circ} \mathrm{C}\right]} \\
\end{array}$ & Polytropic index \\
\hline 0 & \multirow{6}{*}{18.2} & 27.0 & 1.030 \\
\hline 30 & & 29.9 & 1.040 \\
\hline 60 & & 31.4 & 1.045 \\
\hline 90 & & 31.7 & 1.046 \\
\hline 120 & & 32.9 & 1.050 \\
\hline 150 & & 33.7 & 1.053 \\
\hline $\begin{array}{r}\text { Internal diame } \\
d=30\end{array}$ & $\begin{array}{l}\text { eter of tank } \\
4 \mathrm{~mm}\end{array}$ & & $\begin{array}{c}\text { Mean value } \\
n=1.044\end{array}$ \\
\hline
\end{tabular}

In this study, the change of state of the air in the tank is assumed as the polytropic change. It is necessary to examine the optimum position of the thermometry in the tank in order to obtain the accurate polytropic index $n$ from the temperature change in the tank. Then, the thermocouple was installed in the tank, and the thermocouple moved radially, and the temperature change in the tank was measured. Under the test of the valve $C$, the values of the polytropic index obtained by substituting the measurement values of the temperature at the start of charge and that at the end of charge in Eq.
(15) are shown in Table 3 . The mean value of polytropic index $n$ was 1.044 , and the mean value of polytropic index can be obtained at the position of $60 \mathrm{~mm} \sim 90 \mathrm{~mm}$ from the wall surface. This position is correspondent to the position of $0.2 \mathrm{~d} \sim 0.3 \mathrm{~d}$ from the wall surface, where $d$ is the inside diameter of the tank. In this study, the temperature was measured at the position of $0.25 \mathrm{~d}$ from the inner wall surface of the tank.

When the flow characteristic of large solenoid valve is measured by the flow method, the large test equipment is necessary and the power consumption increases. As a example, if the flow characteristic of the tested valve $\mathrm{N}$ ( $50 \mathrm{~mm}$ nominal bore) is measured by the flow method at the upstream absolute pressure of $500 \mathrm{kPa}$, then the air consumption required is about $55 \mathrm{~m}^{3} / \mathrm{min}$ (ANR), and the power of the compressor required is about $350 \mathrm{~kW}$. However, the power of the vacuum pump used for the charge method in this study was $1.5 \mathrm{~kW}$. Therefore, the charge method is the energy saving method in comparison with the flow method.

\section{CONCLUSIONS}

The measurement of the critical pressure ratio and the sonic conductance of the large pneumatic solenoid valve became possible by the charge method. Furthermore, the charge method is the energy saving test method and the low noise test method in comparison with the conventional test method.

\section{ACKNOWLEDGMENT}

The author would like to thank Mr. N. Oneyama, Dr. H. Zhang and Mr. M. Senoo of SMC Corporation for providing the experimental equipment and their helpful advices.

\section{REFERENCES}

1. ISO 6358, Pneumatic fluid Power-Components using compressible fluids-Determination of flowrate characteristics, 1989.

2. Kuroshita, K. and Suzuki, A., Study on Measurement Method of Flow-rate Characteristics of Pneumatic Solenoid Valve, Transactions of the Japan Fluid Power System Society, Vol.33, No.2, 2002, pp.14-19

3. JIS B 8390, Pneumatic fluid Power-Components using compressible fluids-Determination of flowrate characteristics, 2000.

4. Tanishita, I., Engineering Thermodynamics, Syokabou, Tokyo, 1981, pp.65-66.

5. Ishibashi, M. and Takamoto, M.,'Simplified Method to Measure the Reynolds Number Dependence of the Discharge Coefficient of a Critical Nozzle, Bulletin of the National Research Laboratory of Metrology, 2001, 50-1,pp.7-15. 